\title{
Motor vehicle crashes in Pakistan: the emerging epidemic
}

\author{
Adnan A Hyder, Abdul Ghaffar, Tayyeb I Masood
}

\begin{abstract}
Setting-Motor vehicle injuries are increasingly being recognized as a growing public health issue in the developing world. Pakistan is a developing country in South Asia where motor vehicle use has increased since independence in 1947.

Objective-This paper explores the magnitude and impact of injuries from motor vehicle crashes in Pakistan.

Methods-An exhaustive review of published and gray literature, together with a detailed analysis of government data from 1956.

Results-The data indicate a persistent increase in the numbers of motor vehicle crashes, injuries, and fatalities. Changes in the reporting of rates are important to note in evaluating the data. Commercial vehicles contribute disproportionately to these motor vehicle injuries.

Conclusions-There is a need to further the recognition of injuries as a public health issue in this country. Specific exploration of the epidemiological data; intersectoral collaboration between health, law, police and transport; and the development of appropriate information systems, will contribute to an appropriate response by Pakistan.
\end{abstract}

(Injury Prevention 2000;6:199-202)

Keywords: road traffic injuries; motor vehicle crashes; Pakistan; developing countries

Injuries are being recognized as one of the important public health challenges at the dawn of the new century. Intentional and unintentional injuries kill and maim people, often destroy families, and devastate communities. In addition, they present a special challenge as health systems in general are least prepared to respond to this assault. ${ }^{1}$ In developing countries, between $5 \%$ and $20 \%$ of the burden of disease may be attributable to injuries. In many developed countries, injuries are now the leading cause of death among children and young adults. $^{2}{ }^{3}$ Throughout the developing world, injuries together with tuberculosis, cardiovascular diseases, and cancers are the major causes of adult mortality. ${ }^{4}$ Among injuries, those caused by motor vehicle crashes are the leading cause of healthy years of life lost where such estimates are available. ${ }^{6}$

There are an estimated 10 million motor vehicle crashes annually world wide. ${ }^{7}$ These are the leading cause of death in adolescents and young adults. Nearly three quarters of deaths resulting from these crashes occur in develop-

\section{Key points}

- The burden of disease from injuries needs to be recognized as an important public health issue in the developing world.

- Pakistan is a developing nation demonstrating all the features of urbanization and economic growth that portend an increasing risk for motor vehicle injuries.

- Public sector records from the police indicate a persistent growth in the number of motor vehicle crashes, injuries, and fatalities in the country since 1956.

- Commercial and public service vehicles are involved in a majority of reported motor vehicle crashes in Pakistan.

- The public health sector in Pakistan must recognize and respond to this emerging epidemic.

ing countries. ${ }^{8}$ It is projected that motor vehicle crashes (road accidents) will rank third in order of disease burden (measured in disability adjusted life years) in the year 2020, compared with their present ninth ranking. ${ }^{9}$

Pakistan is the seventh most populous country in the world, with a population of 135 million. ${ }^{10}$ It is a nation at the crossroads of economic progress but is still struggling to find a path towards sustainable development. Historically, health policies have been biased towards curative services and treatment rather than prevention. In such an environment, injuries would not be expected to be on the agenda for health decision makers.

In this paper we will analyze existing data on motor vehicle crash injuries in Pakistan to evaluate the magnitude of the problem. Specific objectives for this study are: (1) to estimate the magnitude of motor vehicle crashes; (2) to demonstrate time trends, using historical data; and (3) to assess the impact of motor vehicle crashes on the health of the Pakistani public. In addition, indications of under-reporting and issues of validity and reliability of data being generated from government sources will also be presented.

\section{Methods}

Data for this study come from a number of different sources. A systematic review of electronic database searches, regional indices, and institutional reports was conducted to identify any study on motor vehicle crashes in any part of Pakistan. Police records have been used as a source of data since 1956. Data on crashes were obtained from the Federal Police Research Bureau ${ }^{11}$; for registered vehicles, from
615 North Wolfe Street,

Baltimore, MD 21205, USA

(email: ahyder@jhsph.edu) 


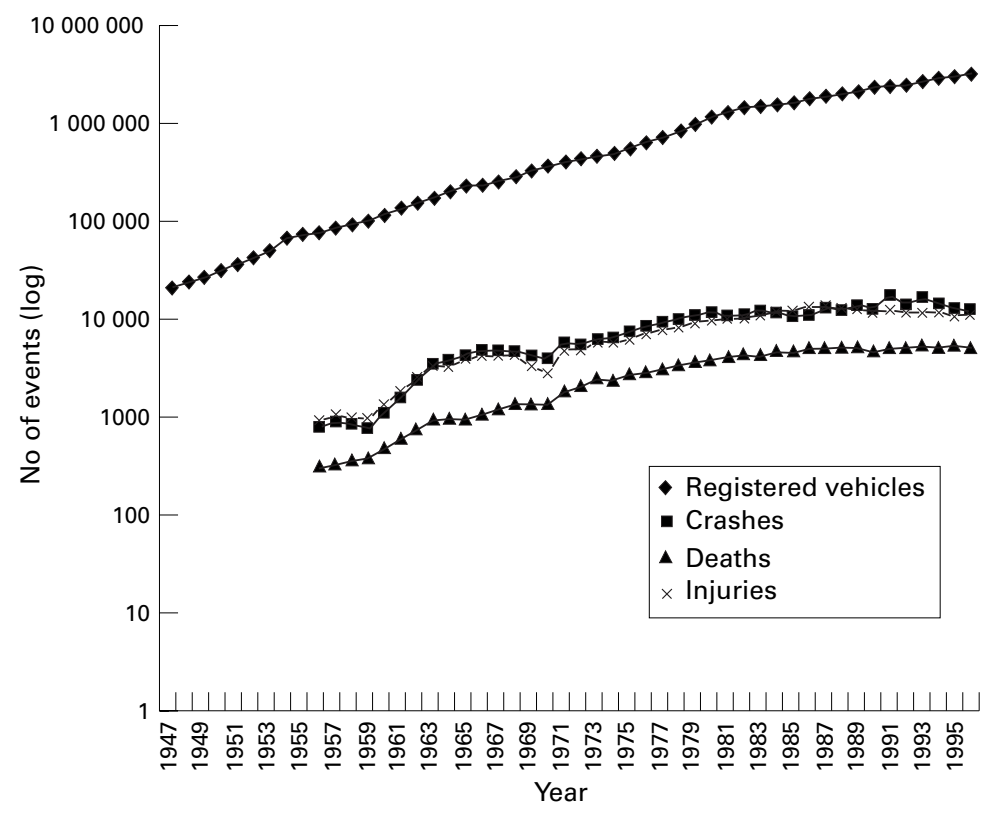

Figure 1 Total number of registered vehicles, total crashes, deaths, and injuries.

the Provincial Departments of Excise and Taxation $^{12}$; and for road kilometers from the Federal Bureau of Statistics, ${ }^{13}$ in Islamabad, Pakistan. Population density, vehicles $/ \mathrm{km}$, motorization level (that is number of vehicles/ 1000 population) and road traffic crashes in the years 1956 to 1996 were used to measure the risk of road traffic injuries. The documents use the nomenclature of "road traffic accidents" and rates, whereas we use "motor vehicle crashes" as the standard terminology in recognition of the fact that most of the "accidents" are potentially preventable. However, in cases where direct public sector data has been used, we have left the terminology as documented originally.

Thirty five in-depth interviews were conducted with the survivors of motor vehicle crashes between May and August 1998. These were done in the hospital on the day on which patients were to be discharged. In addition to time, place, cause of accident, and effectiveness of emergency medical services, they were specifically asked whether police registered a case for that particular crash or not.

Table 1 Change in motor vehicle injury risk factors between 1956 and 1996

\begin{tabular}{lllllll}
\hline Year & $\begin{array}{l}\text { Motor vehicle } \\
\text { registered }(n)\end{array}$ & $\begin{array}{l}\text { Motor vehicle } \\
\text { crashes }(n)\end{array}$ & $\begin{array}{l}\text { Deaths in } \\
\text { motor vehicle } \\
\text { crashes }(n)\end{array}$ & $\begin{array}{l}\text { Motorization } \\
\text { level }\end{array}$ & $\begin{array}{l}\text { Vehicles/km } \\
\text { (vehicle } \\
\text { density) }\end{array}$ & $\begin{array}{l}\text { People/km } \\
\text { (population } \\
\text { density) }\end{array}$ \\
\hline 1956 & 77606 & 796 & 302 & 13.25 & 1.7 & 45.3 \\
1996 & 3838157 & 12626 & 5280 & 25.08 & 11.2 & 152.8 \\
$\%$ Increase & 4846 & 1486 & 1648 & 1793 & 559 & 237
\end{tabular}

${ }^{\star}$ Motorization level: vehicles/1000 people.

Source: Federal Police Research Bureau and Federal Bureau of Statistics, Pakistan.

Table 2 Capture of motor vehicle crash injuries by police records in Pakistan

\begin{tabular}{llll}
\hline & $\begin{array}{l}\text { In-depth } \\
\text { interviews (1998) }\end{array}$ & $\begin{array}{l}\text { Razzak and } \\
\text { Luby (1998) }\end{array}$ & 1996 police records \\
\hline No of injuries (100\%) & 35 & 2048 & $28889-78302^{\star}$ (estimate) $^{19}$ \\
Injuries in police records (\%) & $5(14.28 \%)$ & $793(38.7 \%)$ & 11186 \\
\hline
\end{tabular}

^Estimate based on 1998 data from the other two sources.

\section{Results}

Data on motor vehicles registered, number of motor vehicle crashes, injuries and deaths are shown in fig 1 (log scale) for Pakistan from the earliest record available in the public sector. Pakistan gained independence in 1947, and records are available since then. Figure 1 indicates the steadily increasing trend in the absolute numbers of events throughout the past five decades.

The total number of registered vehicles increased 17 times between 1956 and 1996 (table 1). At the same time, there was a fivefold increase in vehicles on the road, indicative of vehicle density, and a $237 \%$ increase in the number of people $/ \mathrm{km}^{2}$ (population density). During this 40 year period there was a 14 -fold increase in the total number of motor vehicle crashes, while the number of deaths due to road traffic crashes increased 16 times $^{14}$ (table 1).

An extensive review of the data collection and reporting system revealed two important features. Since 1991, government documents have started using total number of "registered vehicles" instead of "vehicles on road" for accident fatality and other rates related with number of vehicles. ${ }^{15-17}$ This change in denominator is more consistent with the reporting from other countries but requires caution for interpreting such rates. For example, fatalities/ 10000 vehicles for 1996 would be 35 when vehicles on road is used, and only 16 when registered vehicles is used as a denominator. This represents a halving (or doubling) of the rate when one or the other denominator is used for crash related rate calculations.

In-depth interviews of motor vehicle crash survivors revealed that only $14.3 \%$ of the interviewees confirmed that the crash in which they were injured was registered by the police. ${ }^{18}$ Another study in Karachi showed that only $38.7 \%$ of road traffic injuries discovered were reported by the local city police. ${ }^{19}$ This indicates that police data may be missing between $61 \%$ and $86 \%$ of motor vehicle crash injuries in Pakistan (table 2). These in-depth interviews also revealed that all the victims were evacuated and transported to hospital emergency rooms by passerby drivers or shopkeepers near the scene of the crash.

Commercial vehicles represent only $12 \%-$ $35 \%$ of the total number of registered vehicles in any given year in Pakistan. Yet they were involved in over $60 \%$ of motor vehicle crashes and $90 \%$ of deaths due to motor vehicle crashes (table 3). These comprise public service vehicles, large transport buses which carry local commuters, and intercity buses on highways.

Table 3 Contribution of commercial vehicles to motor vehicle crashes, Pakistan

\begin{tabular}{lll}
\hline Year & $\begin{array}{l}\text { \% Of commercial to total } \\
\text { number of registered vehicles }\end{array}$ & $\begin{array}{l}\text { \% Of motor vehicle crashes } \\
\text { by commercial vehicles }\end{array}$ \\
\hline 1957 & 35 & 47 \\
1977 & 13 & 65 \\
1997 & 12 & 69
\end{tabular}

Source: Federal Police Research Bureau, Pakistan. 
Table 4 Profile of motor vehicle injuries in Pakistan 1996

\begin{tabular}{lll}
\hline Measure & Formula & Value \\
\hline Motorization level & Vehicles/1000 population & 25 \\
Fatality rate & No of fatalities/100 000 population & 4 \\
Motor vehicle crash fatality rate & Fatalities by motor vehicle crash/10 000 vehicles & 16 \\
Motor vehicle crash injury rate & Injuries by motor vehicle crash/10 000 vehicles & 37 \\
Vehicle density & Vehicles/road km & 25 \\
Death to accident ratio & No of fatalities to number of motor vehicle crashes & 0.41 \\
\hline
\end{tabular}

Since there are several indicators used for motor vehicle injuries, a number of these have been estimated for the most recent year for which all data were available for Pakistan. Table 4 shows the various rates depicting a profile of the motor vehicle injury issue for 1996 in the country.

\section{Discussion}

Pakistan is facing the challenges of a complex epidemiological transition marked by persisting infectious diseases and a rising burden of non-communicable diseases. ${ }^{20}$ Acute respiratory tract infections, malaria, and pulmonary tuberculosis in adults continue to be major public health problems. However, noncommunicable conditions, such as cardiovascular diseases, cancer, and diabetes are emerging as important public health problems. ${ }^{21}$ In the absence of national, epidemiological, and economic data for injuries, there is limited understanding of the magnitude of the problem. Injuries, and particularly motor vehicle crashes, are still not appreciated as a public health problem by the majority of health professionals and public policy experts. Limitations of knowledge, absence of reliable estimates of the current levels of injuries, and traditional views on health and disease, are factors limiting this understanding. In addition, there are general perceptions that motor vehicle crashes are not a health sector concern, rather a police or transport sector issue.

However, initial success in the public health policy arena has been achieved recently due to the efforts of a small group of public health professionals using some of the 40 year data presented in this paper. There has been recognition of the problem and it has been incorporated into the latest national health policy of 1997. In addition, the most recent national development plan - the ninth five year planhas also included this issue..$^{22} 23$

In Pakistan, according to the law, all motor vehicle crashes must be reported to police authorities if there has been an injury, death, or loss of property. From in-depth interviews and a study in Karachi, ${ }^{18}{ }^{19}$ evidence of underreporting has been found and the magnitude of motor vehicle injuries and deaths may be much more substantial than is evident from official statistics. It may be difficult to generalize the results of only two observations to national data on motor vehicle crashes but the evidence for any under-reporting is more important than the precise level of the phenomenon. The range of under-reporting has been used to estimate the potential number of true events for 1996 in Pakistan (table 2). This phenomena is neither restricted to Pakistan nor to the developing world and has direct relevance to national estimates of injuries.

An increase in the population and number of vehicles, along with an expansion in road networks in the past 40 years has increased the risk of exposure for motor vehicle crashes. The current motor vehicle crash registry system is entirely based on police reporting, and their job is to collect data for legal purposes and not for research and public policy. The nature, type of data, and collection methods make additional challenges for road traffic injury researchers.

Another significant finding is that commercial vehicles are contributing disproportionately more towards motor vehicle crashes. One reason may be that commercial vehicles travel many more kilometers than cars, thereby having an increased risk for crashes. Equally important, is that despite a tremendous increase in the total number of vehicles in the last 40 years, the growth in the number of commercial vehicles has not been able to keep pace with the demand for transport reflected by population growth. This, and the profit motive, has led to the frequent practice of overloading these vehicles, which further contributes to more injuries per vehicle crash and to increased crash fatality rates. In addition factors such as poor maintenance of vehicles, poor driver training, and driver fatigue may also be involved.

The impact of changing denominators is important for data analysis and may be responsible for perceived changes in time trends. Although reasons for the decision to change the denominator in 1991 in Pakistan from vehicles on road to registered vehicles are unclear, it has brought the reporting system closer to that of other countries. In addition, registered vehicles can be obtained from vehicle licensing and taxation records with more ease and relatively better precision. However, there is more work to be done in the country so that figures that account for crashes, injuries, or deaths per 100 million vehicle $\mathrm{km}$ can be reported. This will enable a better measurement of risk for injuries and fatalities from road traffic and also facilitate international comparisons.

\section{Implications for prevention}

All of the above factors combine to reflect the severity of motor vehicle crash related injury problems in Pakistan (table 4). The reasons for such a situation need to be explored and factors ranging from bad driving, or inadequate access to health services, to poor enforcement or mechanical failure of vehicles must be considered. However, there is little evidence that the health sector in general is responding to this challenge. The traditional focus on curative services remains and there is little attention to the development and coordination of emergency medical services in the country. This presents a special challenge to initiate prevention strategies in the country.

A critical step to meet this challenge would be an appreciation of the problem by policy makers from all sectors concerned-transport, health, law, and the police. Although an initial step in 
this direction has been taken within the health sector, it needs stronger political commitment and financial support. Road traffic injuries must appear within the national health research agenda and investigations in this field need to be supported. Capacity development for research and implementation in this field will be required and should be considered in institutional and national health development plans.

Public health experts in Pakistan need to carefully study the detailed epidemiology of motor vehicle crashes and injuries, identify related risk factors, and then test culturally appropriate and cost effective interventions. Such findings are central, and will form the basis for launching primary prevention programs to control the motor vehicle injury epidemic in Pakistan.

This study was conducted as part of the academic program at the Health Services Academy, Pakistan with academic support from the Department of International Health, Johns Hopkins University, USA. Some of the data were also derived from work partly funded by the Global Forum for Health Research, Geneva.

1 World Health Organization. New approaches to road safety. Report of a WHO study group. Geneva: World Health Organization, 1987

2 World Bank. The world development report 1993: investing in health. New York: Oxford University Press, 1993.

3 Baker SP, O’Neil B, Ginsburg MJ, et al. The injury fact book. New York: Oxford University Press, 1992.

4 Feachem RA, Kjellstrom T, Murray CJL, et al. The health of adults in the developing world. New York: Oxford University Press, 1992.

5 Murray CJL, Lopez AD. Global comparative assessments in the health sector: disease burden expenditures and intervention packages. Geneva: World Health Organization, 1994.
6 World Health Organization. World health statistics annual. Geneva: World Health Organization, 1999.

7 World Health Organization. New approaches to improve road safety. Geneva: WHO Technical Report Series 781, 1989.

8 Odero W, Garner P, Zwi A. Road traffic injuries in developing countries: a comparative review of epidemiological studies. Trop Med Int Health 1997; 2:445-60.

9 Murray CJL, Lopez AD. The global burden of disease: a comprehensive assessment of mortality and disability from diseases, injuries and risk factors in 1990 and projected to 2020. Cambridge: Harvard University Press, 1996.

10 Population Census Organization. Census 1998. Islamabad: Statistics Division, Government of Pakistan, 1999.

11 Federal Police Research Bureau. Annual reports. Islamabad: Ministry of Interior, Government of Pakistan, 1998.

12 Excise and Taxation Department 1956-1996. Annual reports. Islamabad: Government of Pakistan.

13 Federal Bureau of Statistics. Annual report. Islamabad: Government of Pakistan, 1998.

14 National Transport Research Center. Research reports. Islamabad: Ministry of Communication, Government of Pakistan, 1998.

15 International Road Federation. World road statistics. Washington, DC: IRF, 1997

16 Pakistan Motorway Police. Road safety in Pakistan (Proceedings of a seminar). Islamabad: Government of Pakistan, 1999.

17 Traffic Police. Presentation to Chief Minister of Punjab. Lahore: Government of Pakistan, 1998.

18 Health Services Academy. Report of in-depth interviews with survivors of road accidents. Islamabad: Ministry of Health, Government of Pakistan, 1998.

19 Razzak JA, Luby SP. Estimating deaths and injuries due to road traffic accidents in Karachi, Pakistan, through capture-recapture method. Int $\mathcal{F}$ Epidemiol 1998;27:86670 .

20 Ministry of Health. Situation analysis of health sector in Pakistan. Islamabad: Government of Pakistan, 1995.

21 Pakistan Medical Research Council. National health survey of Pakistan 1990-94. Islamabad: Ministry of Health, Government of Pakistan, 1997.

22 Ministry of Health. National health policy. Islamabad: Government of Pakistan, 1997.

23 Planning Commission. Ninth five year plan. Islamabad: Government of Pakistan, 1998.

\section{Anniversary of the first pedestrian fatality in North America}

September 1999 was the 100th anniversary of the first known automobile fatality in North America. The victim was Henry Hale Bliss who was struck by an electric (!) automobile in New York. He was reported to have died while turning to help a woman out of a trolley and it is said that the car was driven by the chauffeur of a physician who assisted at the scene. Various estimates put the number who have subsequently been killed by cars at 30 million world wide and 500000 in North America. Several newspapers commemorated the event and I have excerpted some of their comments.

Amanda Bosma, writing in the Winnipeg Free Press noted: "In Toronto, they buried a car; in San Francisco, they stenciled silhouettes of dead bodies onto sidewalks; and in Winnipeg, they urged people to stay off the roads. It was all part of a continent-wide campaign to remind people "there was Bliss before cars" and to urge them "to consider car pooling, transit, and cycling as alternative ways to get to work".

The US Department of Transportation issued a press release coinciding with the anniversary that focused on the safety of millions of children heading back to school. For once the emphasis was right: It notes that "alert, smart drivers can help prevent crashes that kill and injure children and pedestrians of all ages". "A child versus a car is an unfair fight that the child always loses. Children rely on adults for safety".

The release concluded with tips for motorists, noting that it is hard for motorists to see short children; that children have underdeveloped peripheral vision; have difficulty judging speed, spatial relations, and distance. It also mentions that drivers in school areas should expect children to be present. One observer commented, "From my perspective, the suggestion that motorists are responsible for pedestrians' safety is a new departure for DOT, as is the emphasis on prevention of crashes".

Some reports note that pedestrian deaths have declined in recent years, but attribute this to a fall in walking, as more people realize that walking is dangerous, and "drivers are no longer caring or cautious". Some even claim that drivers are purposely intimidating pedestrians from using their legal rights-of-way. 